\title{
SIMILARITIES AND DIFFERENCES BETWEEN SMOKING AND NON-SMOKING TEN-YEAR-OLD CHILDREN IN PRIMARY SCHOOLS
}

\author{
Drahoslava Hrubá1, Iva Žaloudíkováa, Halina Matějová1 \\ ${ }^{1}$ Faculty of Medicine, Masaryk University, Brno, Czech Republic \\ ${ }^{2} F$ aculty of Education, Masaryk University, Brno, Czech Republic
}

\section{SUMMARY}

Background: For the majority of smokers, smoking is related to other forms of risk behaviour, especially poorer eating habits. The primary preventive educational programme "No smoking is a norm" focuses on children of younger school age (under $10 \mathrm{yrs}$ ), enables comparison and statistical evaluation of whether there are any differences (and which) between ten-year-olds with various smoking experiences, with special attention paid to their exposure to the influence of smokers, and their eating habits.

Methods: Analysis of data gained from a questionnaire compared groups of boys and girls, smokers and non-smokers, and children from families with no smokers, occasional smokers, and frequent smokers. Statistical significance of the differences was tested in the EPI INFO programme by means of the $\chi^{2}$ test.

Results: From 1,082 children, almost one quarter (22.9\%) have already tried smoking, boys more frequently $(25 \%)$ than girls (19\%) $(\mathrm{p}<0.05)$; and almost $7 \%$ smoked repeatedly. The household is the most frequently stated environment for accessing cigarettes in children: $51 \%$ of children are given cigarettes by their parents, siblings, grandparents or other relatives, another almost 17\% take cigarettes themselves from unprotected stock. From 246 children who have smoked, more than one third were offered cigarettes by their friends, and some (4\%) even bought them. Children with smoking experience more often come from smokers' families and more often have smoking siblings and friends who offer them cigarettes. Children claimed to have consumed alcoholic drinks over the past month, repeatedly smoking more often than those with one attempt (aprox. $81 \%$ vs $58 \%$ ) and never smokers (32\%). S mokers also more frequently ate salty snacks such as crisps, sausages, and fast foods. The circumstance of whether there are smokers in the child's household or not significantly influenced children's opinions on the smoking of men/boys and women/girls (fewer critics and more admirers in smokers' families), selection of friends, availability of cigarettes, and smoking behaviour of the children.

Conclusion: The examination of a cohort of ten-year-olds in a semi-longitudinal study confirmed the growing trend of experimenting with smoking. Strong relations to smoking behaviour in families were identified - such that influence a more tolerant approach to parents' smoking, selection of smoking or non-smoking friends, more frequent consumption of alcohol and salty snacks.

Key words: ten-years aged children, smokers/no-smokers, differences

Address for correspondence: D. Hrubá, Dept. of Preventive Medicine, Faculty of Medicine, Masaryk University, Komenského n. 2, 66243 Brno, Czech Republic. E-mail: hruba@ med.muni.cz

\section{INTRODUCTION}

The generally accepted notion is that smoking, for most smokers, is also related to other risk behaviors - especially poorer eating habits. Smokers tend to consume more alcoholic drinks, coffee and meat, and a lesser quantity of fruit, vegetable, milk, and dairy products. Out of the frequent studies that have described differences in adults' eating habits, the recent work of Ma et al. (1) can be mentioned, and similar differences were demonstrated in adolescents e.g. by Wilson et al. (2, 3) or Flouris (4). In our work we have shown such trends in high-school students (5) as well as adults (6).

The educational primary preventive programme "No smoking is a norm" focuses on children of younger school age and besides anti-smoking intervention it also supports education in terms of better eating habits and nutritional recommendations, increasing physical activities and friend interpersonal relationships between children. In terms of nutrition, the children are informed about optimal ratios of eating individual foods according to the "food pyramid" and attention is paid mainly to increased consumption of fruit and vegetables (with the use of the " 5 a day" programme and the fairy story of Knight Vitamin C and his helpers), as well as milk and dairy products (using the "Elixir M" programme). Through various "homework" tasks children are motivated to bring their school knowledge of nutritional recommendations into their homes; this expansion is also supported by informative letters and checklist questionnaires aimed at finding out the effect of the programme.

The cohort of children who have followed the programme from their 1st grade, as well as a control group of children not influenced by the programme, are now in their 4th grade in 26 co-operating schools. The questionnaire survey, which took place prior to the launching of the lesson block in the 4th grade, showed that in the category of ten-year-olds the number of experimenting smokers again increased compared to the previous period. This enables a comparison and statistical evaluation of any differences 
between ten-year-olds with various smoking experiences with special attention paid to their exposure to the influence of smokers, and their eating habits.

\section{METHODOLOGY}

For the purposes of monitoring trends in knowledge, opinion, and behavioural development of children during the prospective course of the intervention study some data is listed regularly: opinions (admiration, criticism, indifference) towards smoking women/girls and men/boys, exposure of children to smokers and smoking environment in their homes, consumption of alcoholic drinks and selected groups of food ("healthy" - fruit, vegetables, dairy products, and "unhealthy" - smoked meat products, typical fast food products, salty crisps and similar snacks, sweets). Consumption of food was related to the day of the previous questionnaire survey and tasting of alcohol to the previous month. For better orientation the most frequent examples were offered under the individual food commodities (the children ticked them), with the possibility to add further ones that were missing in the offered list. When recording answers in the analytical programme, numbers of portions (pieces) of individual food types the child had eaten the day before was considered. The "vegetables" included potatoes, whereas “dairy products" did not cover butter or various sweet products containing milk as presented by advertising. 14 questionnaires were dismissed from the survey as the respondents ticked all the listed items.

For experiments with smoking cigarettes it was necessary to state whether a child had ever tried smoking (once, repeatedly) as well as the fact of whether he/she had smoked in the previous week. To evaluate the influence of the smoking environment, children provided information on whether anyone smokes in their household and whether they have any smoking friends. Smokers were asked to say how they got hold of cigarettes.

The data analysis was carried out after the comparison of groups of boys and girls, smokers and non-smokers, coming from families where nobody smokes, or smokes occasionally, or smokes frequently without limitation. Statistical significance of the differences was tested in the EPI INFO programme by means of the $\chi^{2}$ test.

\section{RESULTS}

In the 4th grade the pre-test questionnaire was filled in by 1,082 children, 512 of whom (47.2\%) are included in the group with the programme and 570 pupils (52.7\%) represent the control group. The share of boys (49.7\%) and girls (50.3\%) was basically equal.

Almost one quarter of the children (22.9\%) has already tried smoking, boys more frequently (25\%) than girls (19\%); this difference is statistically significant $(\mathrm{p}<0.05)$. Out of 246 children who confessed to smoking, two times more boys than girls smoked repeatedly and 35 children reported smoking in the last week prior filling in the questionnaire (Table 1). When asked about consumption of alcoholic drinks in the previous month, $40 \%$ of the children provided positive answers; girls tasted alcohol less frequently than boys, but the differences were not statistically
Table 1. Children' experiences with the legal drug use (\%)

\begin{tabular}{|c|c|c|c|}
\hline \multirow{2}{*}{ No. of children } & Boys & Girls & Whole group \\
\hline & 527 & 535 & 1,082 \\
\hline Never tried to smoke yet & 75.0 & $81.0 *$ & 77.1 \\
\hline One single attempt & 17.2 & 15.0 & 16.1 \\
\hline Smoked repeatedly & $7.8^{* *}$ & 4.0 & 6.8 \\
\hline Smoking during the last week & 3.4 & 3.1 & 3.2 \\
\hline \multicolumn{4}{|l|}{ During the last month: } \\
\hline No alcoholic beverage & 56.8 & 64.6 & 60.3 \\
\hline One single drunk & 26.8 & 25.7 & 26.6 \\
\hline $\begin{array}{l}\text { Drank repeatedly } 2 \text { or more } \\
\text { alcoholic beverages }\end{array}$ & $16.4^{* * *}$ & 9.7 & 13.1 \\
\hline
\end{tabular}

Statistic significance between boys and girls:

$*=p<0.05 ; * *=p<0.01 ; * * *=p<0.001$

Table 2. The sources of tobacco products (per cent of 246 smoking children)

\begin{tabular}{|l|c|}
\hline Siblings & $12.6 \%$ \\
\hline Parents & $15.0 \%$ \\
\hline Other relatives & $23.2 \%$ \\
\hline Took himself/herself at home & $16.7 \%$ \\
\hline Together at family environment & $67.5 \%$ \\
\hline Friend & $37.4 \%$ \\
\hline Bought himself/herself & $3.7 \%$ \\
\hline
\end{tabular}

significant. The most frequently consumed drink was beer (14.7\% children) and wine (7.1\%), but children also had access to liquor and distilled alcohol (4.1\%). There are no significant differences in the preference for various types of drink among boys and girls. A warning signal is the repeated consumption of different drinks containing alcohol, which was stated by $13 \%$ of the children, more frequently by boys than by girls (Table 1 ).

When asked about the source of their cigarettes, children mentioned all the available possibilities, i.e. some of them selected multiple options. For the 246 children who had already tried smoking, the most significant source of available cigarettes is their home: children get cigarettes from their parents, siblings, grandparents and other relatives, or they take cigarettes themselves from unprotected stock. More than one third of children said they were offered cigarettes by their friends (boys more frequently $-43.5 \%$, than girls $-35.0 \%$, $\mathrm{p}<0.05)$. Some of the children even claimed to have bought cigarettes (Table 2).

Opinions on smoking of their peers and adults of different sexes, expressed through "marks" (1+2 as admiration, 3 as indifference, 4+5 as criticism) significantly differ between children who never tried smoking, those who have tried once, and those who smoked repeatedly (Table 3). Among non-smokers, there are significantly more critics, fewer children with an unspecified opinion, and admiration was expressed only by a few individuals. However, among children with smoking experience there are more admirers and neutrals, and fewer critics. This becomes especially evident in different approaches to smoking between 
Table 3. Differences between never smoking and experimenting (once or repeatedly) children (\%)

\begin{tabular}{|c|c|c|c|}
\hline Smoked: & Never & Once & Repeatedly \\
\hline No. of children & 836 & 173 & 73 \\
\hline Admire smoking women & 0.9 & $9.4^{* * *}$ & 2.8 \\
\hline Admire smoking men & 2.4 & $8.7^{*}$ & $26.8^{* * * *}$ \\
\hline Criticise smoking women & 91.7 & $74.7^{\text {*** }}$ & $57.7^{* * *}$ \\
\hline Criticise smoking men & 85.9 & $66.8 * *$ & $38.1^{* * *}$ \\
\hline Unconcerned - to smoking women & 7.4 & $15.9 * *$ & $39.5^{* *}$ \\
\hline to smoking men & 11.9 & $24.5^{* *}$ & $35.1^{* *}$ \\
\hline Has smoking friend & 16.4 & $54.4^{* * * *}$ & $74.0^{* *}$ \\
\hline Smoking at home: never & 65.5 & 48.3 *** & $37.0 * * *$ \\
\hline occasionally & 15.4 & 18.0 & 15.1 \\
\hline very often & 19.0 & $33.7^{* *}$ & $46.6^{* *}$ \\
\hline Sources of cigarettes: siblings & & 9.3 & $20.5^{*}$ \\
\hline took himself/herself & & 11.0 & $30.1^{* *}$ \\
\hline bought himself/herself & & 3.5 & $12.4^{*}$ \\
\hline \multicolumn{4}{|l|}{ During last month: } \\
\hline drank no alcohol & 67.8 & $41.6^{* *}$ & $19.2^{* * * *}$ \\
\hline drank repeatedly & 9.4 & $24.3^{* *}$ & $28.8^{* * *}$ \\
\hline \multicolumn{4}{|l|}{ During last day: } \\
\hline ate no fruit & 9.8 & 13.6 & 14.1 \\
\hline ate no vegetable & 15.5 & 17.3 & 20.0 \\
\hline ate no milk/dairy products & 7.9 & 5.9 & 4.2 \\
\hline ate no salt delicacy & 40.0 & $33.1^{*}$ & $21.1^{* *}$ \\
\hline ate no sweet delicacy & 39.1 & 32.0 & 38.9 \\
\hline \multicolumn{4}{|l|}{ Ate recommended amount of: } \\
\hline fruit (3 and more) & 38.2 & 42.1 & 36.6 \\
\hline vegetables ( 4 and more) & 13.6 & 14.3 & 18.6 \\
\hline dairy products (3 and more) & $13.1^{*}$ & 38.3 & 31.0 \\
\hline \multicolumn{4}{|l|}{$\begin{array}{l}\text { Ate less than recommended amount } \\
\text { of }\end{array}$} \\
\hline fruit (1-2) & 52.0 & 49.3 & 44.4 \\
\hline vegetables (1-3) & 70.9 & $61.4^{*}$ & 68.4 \\
\hline dairy products (1-2) & 55.5 & $64.8^{*}$ & 55.9 \\
\hline
\end{tabular}

Statistic significance between never smoking, once a repeatedly smoking children: ${ }^{*}=p<0.05 ;{ }^{* *}=p<0.01 ;{ }^{* * *}=p<0.001$

children who smoked repeatedly and those who had tried once. Critical opinions dominate also in the group of repeatedly smoking children, but according to recent developments shift in the frequency of indifferent opinions towards admiration, especially of smoking men can be expected.

Children with smoking experience more often come from smoking families with easier availability of cigarettes and more often have smoking siblings who offer them cigarettes. They also live in a smoking environment outside the family as they are more likely to have smoking friends (Table 3).

Experimenting smokers more frequently consumed alcoholic drinks in the past month, on single occasions and repeatedly, alternating two or more types. In answers to questions regarding consumption of selected types of food in the day before, children with smoking experience more often claimed to have eaten salty snacks (crisps, crackers, sticklets), smoked meat and "fast food" 
Table 4. Differences between children living in smoking and non-smoking families (\%)

\begin{tabular}{|c|c|c|c|}
\hline Smoking at home & Never & Occasionally & Often \\
\hline No. of children & 654 & 167 & 245 \\
\hline Admire smoking women & 1.5 & 2.5 & $3.8 *$ \\
\hline Admire smoking men & 3.9 & 3.0 & $7.9 * *$ \\
\hline Criticise smoking women & 90.2 & $84.7 * *$ & 79.9 *** \\
\hline Criticise smoking women & 84.0 & $75.0^{* * *}$ & $72.9^{* * * *}$ \\
\hline Tried to smoke & 16.9 & $24.0 *$ & $36.8 * * *$ \\
\hline Tried to smoke repeatedly & 4.2 & 6.0 & $13.5^{* *}$ \\
\hline Tried to smoke last week & 1.5 & 1.2 & $9.4^{* * * *}$ \\
\hline Drank alcohol last month & 33.3 & $48.5^{* * *}$ & $49.4^{* * *}$ \\
\hline Drank alcohol repeatedly & 11.5 & $15.6 * *$ & $16.9 * *$ \\
\hline Has smoking friend & 20.6 & 25.9 & $41.2^{* * * *}$ \\
\hline \multicolumn{4}{|l|}{ Source of cigarettes: } \\
\hline siblings & 1.4 & $4.8^{* *}$ & $5.4^{* * *}$ \\
\hline parents & 1.2 & $8.4 * * *$ & 6.1 *** \\
\hline took at home & 2.0 & $3.6^{*}$ & $9.0 * * *$ \\
\hline friend & 6.7 & 4.8 & 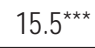 \\
\hline Ate no fruit & 9.9 & 10.8 & 13.7 \\
\hline Ate no vegetable & 15.3 & 16.3 & 18.9 \\
\hline Ate no dairy products & 7.4 & 7.8 & 6.7 \\
\hline Ate no salt delicacy & 42.2 & $29.9 * * *$ & $31.4 *$ \\
\hline Ate no sweet delicacy & 40.0 & $28.7 * *$ & 38.3 \\
\hline \multicolumn{4}{|l|}{ Ate recommended amount of: } \\
\hline fruit (3 and more) & 38.4 & 41.6 & 36.5 \\
\hline vegetable (4 and more) & 15.3 & $8.4^{*}$ & 13.4 \\
\hline dairy products (3 and more) & 36.2 & 38.6 & 35.8 \\
\hline \multicolumn{4}{|c|}{ Ate less than recommended amount of: } \\
\hline fruit (1-2) & 51.7 & 47.8 & 49.8 \\
\hline vegetable (1-3) & 69.4 & 75.3 & 67.7 \\
\hline dairy products (1-2) & 56.5 & 53.6 & 57.5 \\
\hline
\end{tabular}

Statistic significance between children from homes with total ban of smoking and those with parcial and no restriction of smoking: ${ }^{*}=p<0.05 ;{ }^{* *}=p<0.01 ;{ }^{* *}=p<0.001$

(French fries and hamburgers). Information about the frequency of other selected foods (fruit, vegetables, milk and dairy products, sweets) were similar in all groups (see Table 3).

The question "does anyone smoke at home" did not intend to find out about the smoking of individual family members but whether there are any restrictive rules applied to smoking. The selection of the option "smoking sometimes" may point to the possibility that smoking family members observe the rule of not smoking in the home or the source of exposure may be an occasional smoking visitor. The circumstance of whether there are smokers in the child's home or not significantly influenced children's opinions on the smoking of men/boys and women/girls (fewer critics and more admirers in smokers' families), selection of friends, access to cigarettes, and smoking behaviour of the children.

Adverse effects were most frequently demonstrated in case of children in whose homes smoking is not restricted in any way (Table 4). Surprisingly, no differences were found in the frequency of questions relating to children's nutrition, with the exception of more frequent consumption of salty snacks by ex- 
perimenting smokers. Absence of consumption of "good food" (fruit, vegetables, dairy products) in the previous day and their consumption in the recommended amounts was similar in all the groups of children. Most children were given at least one portion from each of the monitored groups of "good food" during the previous day (Table 4).

Girls, compared to boys, consume slightly more portions of fruit per day (2.6 vs. 2.0), vegetables (2.16 vs. 1.65$)$ and dairy products (2.2 vs. 2.0) and on the other hand slightly less salty food (0.94 vs. 1.1), but the differences are not statistically significant. Both groups of children said they had eaten sweets with a similar average frequency ( 0.87 vs. 0.84$)$.

\section{DISCUSSION}

An extensive overview of the reference literature divides the determinants of adolescent smoking into three groups: individual (mainly knowledge and attitudes), social (smoking of parents and other relatives, socio-economic status of the family and smokers), and society-related (legislation, advertising, media, overall degree of tolerance to adverse effects) (7). Whereas most of the expert literature focuses on pubescents and adolescents, our study monitors the selected determinants influencing the behaviour of younger children aged 6-10 years.

Our results illustrating relations between the frequency of smoking attempts of ten-year-olds and their exposure to the models of smoking adults confirm a previous study carried out within the same set (8) and are consistent with other studies. In our set, too, family members are the most frequent providers of cigarettes to children.

Significant influence of peers is often described in studies focusing on smoking of adolescents $(7,9)$. Our study, however, shows that differentiation during the process of making friends with respect to their smoking or non-smoking status occurs actually before the onset of puberty and relates to the smoking behaviour of the family in which the child grows up. Standards of behaviour that are formed by the family in pre-school age are therefore supported by equal models at the time of school age and influence the children's opinions and behaviour well before puberty, which is often considered a critical period during which children are most prone to adopt all sorts of risky behaviour. Children's attitude towards smoking, which is monitored by the indicator of admiration or criticism of smokers in our study, changes significantly and unfavourably: in the 2nd grade critical opinions of smoking men were expressed by $92 \%$ of children and $96 \%$ were critical of smoking women. After two years there were approximately $5 \%$ less critics of smoking among no-smokers (86\% for men, $92 \%$ for women), but smoking of adults is criticised only by $38 \%$ or $58 \%$ children who had tried smoking themselves.

Differences between eating habits of adult and adolescent smokers and non-smokers have been described by many authors $(1,2,3)$; the dominant characteristic is mainly the reduced consumption of fruit, vegetables and dairy products, as well as an increased intake of meat, coffee, and alcoholic drinks. The results of frequency questionnaires confirm also work monitoring different content of selected micro-nutrients in smokers and non-smokers. The reduced content of vitamin $\mathrm{C}$ and $\beta$-carotenes found in smok- ers does not relate only to higher need due to chronic inflammatory changes, but also to the reduced intake of their natural sources. On the other hand, average values of micro-nutrients that are found mainly in meat (vitamins A, E, B6, B12 and iron), were similar in both smokers and non-smokers (10).

Changes in eating habits of smokers are usually explained by smokers' subjective experience telling them that certain foods and drinks reduce their enjoyment of smoking, and others increase it. Foods that cause a bad taste of cigarettes are most frequently said to be dairy products, fruit, vegetables, and non-caffeinated drinks (11). The opposite effect is said to be caused by coffee and alcohol (11), which are assumed to interact in a psycho-pharmacological way with nicotine $(12,13)$.

Children in our study, aged ten, showed certain differences in eating habits according to whether they had or had not tried smoking yet, but these were not statistically significant, except for the consumption of smoked meat, hamburgers, crisps, and similar salty snacks and occasional tasting of alcoholic drinks. However, it cannot be assumed that the children's liking of these foods has been influenced by the pleasure of smoking cigarettes with which they are just beginning.

Another reason for the differences in children's eating habits is the presumption that in the families of smoking adults whose children more frequently experiment with smoking from an early age, less attention is paid to expert nutritional recommendations (14); and problems occur especially in families where parents belong to lower social and less educated population groups (15). However, this hypothesis was not confirmed by our study: the frequency in consumption of individual monitored foods was similar in smokers' and non-smokers' families, again with the exception of salty snacks.

Whereas nutrition of younger school-age children is influenced by the family or school during the day (morning snacks, lunches), the frequency of consuming salty and sweet snacks is determined by the children through purchases with their pocket money. It is possible that salty snacks may be offered to children more frequently in smokers' families, as the study of Johnson (15) and our study too, have confirmed. It is also possible that the higher preference for very salty foods by the experimenting smokers could be, at least partially, influenced by biological sensory factors based on the genetically determined perception of flavours. In this respect, a single study was found in the available literature - the authors proved that inherited differences in the perception of a bitter taste do relate to smoking and that taste can be significant motivation for smoking (16).

The fact that most of the children from our set do not consume the recommended portions of fruits, vegetables and dairy products may relate to the fact that parents have not yet accepted the experts' recommendations regarding a healthy diet and that the consumption of such foods is not recommended for children (17). The higher frequency of consumption of alcoholic drinks in smokers' families demonstrates their availability to children, as well as the more tolerant approach of the parents. It should be noted that the survey took place in the autumn, before Christmas and New Year's celebrations, and that the data is related to the period of the previous month.

Our study does have certain limitations; it does not cover a representative selection of the set of children as the data is collected in schools that have voluntarily applied to work under 
the "No smoking is a norm" programme. Subjective answers of children could not be objectively verified and information about the consumption of various foods was collected for one single day only, which preceded the administration of the questionnaire.

On single days during the week, nutritional consumption usually varies and the collection of data was not carried out using the classical recall method; therefore it is necessary to consider the results on eating habits as only approximate. However, their acceptable answer value can be confirmed by obvious agreement with the data of the previous survey in which children from the same cohort stated which foods they consume often (not published) and also from the questionnaire survey among their parents describing how many portions of fruit, vegetables, and dairy products their children usually eat per day (17).

In our study we did not analyse the social position of the families either; although the children were asked to state the highest education level of their parents; in many cases the data was missing and therefore not analysed. Despite the fact that it has been repeatedly verified that the socio-economic situation of families does not influence children's smoking $(18,19)$ we will include this indicator in the next survey asking teachers to confirm the answers.

\section{CONCLUSIONS}

The survey of a set of ten-year-olds under the influence of the "No smoking is a norm" programme and their peers from the control group confirmed the increasing trend of children experimenting with smoking. A strong relationship to smoking in families has been shown, as well as the fact that they also influence the selection of smoking or non-smoking friends. Experimenting child smokers were significantly more tolerant of the smoking of adults, especially men. They also tended to consume alcoholic drinks and salty snacks more often. There is no doubt that the tolerant attitude of Czech society, supported by the unwillingness of politicians to create better conditions for primary prevention of tolerance of legal drug consumption is clearly reflected in the increasing trends of risky behaviour among children. Most children do not eat according to the expert nutritional recommendations (judged by the number of daily portions) and do not learn correct patterns of healthy nutritional behaviour.

As smoking, alcohol, and incorrect nutrition are the main risk factors for chronic diseases and premature deaths, the results of the study are very important for the development of the health of the generation of recent schoolchildren.

\section{Acknowledgements}

The study is supported by the League against Cancer Prague and the Research Project MŠMT 0021622421.

\section{REFERENCES}

1. Ma J, Hampl JS, Betts NM. Antioxidant intakes and smoking status: data from the continuing survey of food intakes by individuals 1994-1996. Am J Clin Nutr. 2000 Mar;71(3):774-80.

2. Wilson DB, Nietert PJ. Patterns of fruit, vegetable, and milk consumption among smoking and non-smoking female teens. Am J Prev Med. 2002 May;22(4):240-6.

3. Wilson DB, Smith BN, Speizer IS, Bean MK, Mitchell KS, Uguy LS, et al. Differences in food intake and exercise by smoking status in adolescents. Prev Med. 2005 Jun;40(6):872-9.

4. Flouris AD, Faught BE, Klentrou P. Cardiovascular disease risk in adolescent smokers: evidence of a "smoker lifestyle". J Child Health Care. 2008 Sep;12(3):221-31.

5. Nová E, Hrubá D, Kachlík P. Adolescents’ smoking and associations with other types of unwanted youth behaviour. Hygiena. 1997;42(4):234-8. (In Czech.)

6. Kukla L, Hrubá D, Tyrlík M. Nutrition of pregnant women: differences between smokers and non-smokers during pregnancy. Gynekolog. 1999;8(3):112-8. (In Czech.)

7. Geckova A, van Dijk JP, van Ittersum-Gritter T, Groothoff JW, Post D. Determinants of adolescents' smoking behaviour: a literature review. Cent Eur J Public Health. 2002 Sep;10(3):79-87.

8. Hrubá D, Žaloudíková I. Where do our children learn to smoke? Cent Eur J Public Health. 2008 Dec;16(4):178-81.

9. Musick K, Seltzer JA, Schwartz CR. Neighbourhood norms and substance use among teens. Soc Sci Res. 2008 Mar;37(1):138-55.

10. Northrop-Clewes CA, Thurnham DI. Monitoring micronutrients in cigarette smokers. Clin Chim Acta. 2007;377(1-2):14-38.

11. McClernon FJ, Westman EC, Rose JE, Lutz AM. The effects of foods, beverages, and other factors on cigarette palatability. Nicotine Tob Res. 2007 Apr;9(4):505-10.

12. Rose JE, Brauer LH, Behm FM, Cramblett M, Calkins K, Lawhon D. Psychopharmacological interactions between nicotine and ethanol. Nicotine Tob Res. 2004 Feb;6(1):133-44.

13. Gilbert DG, Dibb WD, Plath LC, Hiyane SG. Effects of nicotine and caffeine, separately and in combination, on EEG topography, mood, heart rate, cortisol, and vigilance. Psychophysiology. 2000 Sep;37(2):58395.

14. Crawley HF, While D. Parental smoking and the nutrient intake and food choice of British teenagers aged 16-17 years. J Epidemiol Community Health. 1996 Jun;50(3):306-12.

15. Johnson RK, Wang MQ, Smith MJ, Connolly G. The association between parental smoking and the diet quality of low-income children. Pediatrics. 1996 Mar;97(3):312-7.

16. Cannon DS, Baker TB, Piper ME, Scholand MB, Lawrence DL, Drayna DT, et al. Associations between phenylthiocarbamide gene polymorphisms and cigarette smoking. Nicotine Tob Res. 2005 Dec;7(6):853-8.

17. Hrubá D, Žaloudíková I. The role of the family in the development of some of the children's attitudes towards smoking and their smoking habits. Hygiena. 2008;53(4):135-40. (In Czech.)

18. U.S. Department of Health and Human Services. Tobacco use among U.S. racial/ethnic minority groups: African Americans, American Indians and Alaska Natives, Asian Americans and Pacific Islanders, and Hispanics. A Report of the Surgeon General. Atlanta: U.S. Department of Health and Human Services, Centers for Disease Control and Prevention, National Center for Chronic Disease Prevention and Health Promotion, Office on Smoking and Health; 1998.

19. Ashley OS, Penne MA, Loomis KM, Kan M, Bauman KE, Aldridge M, et al. Moderation of the association between parent and adolescent cigarette smoking by selected sociodemographic variables. Addict Behav. 2008 Sep;33(9):1227-30.

Received April 8, 2009

Accepted in revised form September 24, 2009 